\title{
Analysing Critical Success Factors for Supporting On-line Shopping
}

\author{
Maria Leonilde R. Varela \\ Department of Production and Systems, School of Engineering, University of Minho, \\ Guimarães, Portugal \\ Goran D. Putnik \\ Department of Production and Systems, School of Engineering, University of Minho, \\ Guimarães, Portugal \\ Maria do Sameiro Carvalho \\ Department of Production and Systems, School of Engineering, University of Minho, \\ Guimarães, Portugal \\ Luís Ferreira \\ Polytechnic Institute of Cávado and Ave, Campus do IPCA, Barcelos, Portugal \\ Maria Manuela Cruz-Cunha \\ Polytechnic Institute of Cávado and Ave, Campus do IPCA, Barcelos, Portugal \\ Algoritmi Research Centre, University of Minho, Portugal
}

V. K. Manupati

School of Mechanical Engineering, Division of Manufacturing, VIT University, Vellore, Tamil Nadu, India

\section{K. Manoj}

School of Mechanical Engineering, Division of Manufacturing, VIT University, Vellore, Tamil Nadu, India

\begin{abstract}
On-line shopping is nowadays is a highly frequent action but there are several critical factors that have to be considered for enabling websites and platforms to be able to offer all necessary requisites for guaranteeing user friendly, secure and also enjoyable shopping experiences to clients, offering them exactly what they expect to buy, and quickly find, among a huge offer available on-line. In this paper a set of considered critical success factors are analysed on a set of top ranked websites, about luxurious furniture, to understand to what extent these critical factors are satisfied. The results can be taken into consideration for implementing a successful businesses through e-commerce from herein analysed perspectives.
\end{abstract}

Keywords: On-line shopping; critical success factors; e-Commerce, Payment security, Website userfriendliness, Marketing strategy, website quality.

\section{INTRODUCTION}

On-line shopping is growing fast as an interesting alternative way of buying experience, which has emphasized the relevance of the growing instrumentalization usefulness of the web 
through websites and platforms for supporting e-commerce (Alturas, Santos \& Brites, 2006). Essentially, e-commerce is a type of e-business involving goods, services and information in which the parties involved do not always meet physically but interact electronically. The benefit of e-commerce is of course evident. For example, the potential of placing orders, transferring sales data and inventory information, and conducting the transactions online can significantly reduce business operations cost and increase the speed of business activities.

Given the existing competitiveness in the nowadays global market context, there is an increasing need to reach the maximum number of customers within particular niche markets (Abdallah \& Jaleel, 2014). E-commerce provides many opportunities for business to reach markets that have never been possible to reach before the Internet age. Therefore, e-commerce can create significant value and generate extra sales through the virtual marketplace. Although e-commerce is already being widely explored, there is still considerable margin of growth to its maturity (Ascensão, 2011). Furthermore, there is no guarantee that companies selling their products and services through Internet channels will be successful. Many businesses have now realized that installing computer networks inside the company and creating a website may appear easy. But building a profitable business to fulfil customer's orders online is actually a lot harder. A major challenge for e-commerce success lies in the question of how to use ecommerce to help create a sustainable competitive advantage (Bandyopadhyay, 2010).

There are a vast number of studies demonstrating the successful implementation of ecommerce, in many industrial sectors (Ascensão, 2011), which led to a strong motivation for this work, in order to further the study of the critical success factors for implementing successful businesses through e-commerce from multiple perspectives.

Thus, in this paper, a study of the whole process of on-line shopping, with special focus on critical success factors analysis is presented and discussed. The paper is organized as follows. In section 2, a brief description of the market behind e-commerce is presented. In section 3 an extensive review on the state of the art is included, with the research gap identified. Section 4 proposes a multi-perspective critical success factor analysis and discusses, in detail, each of the critical success factors to be considered when putting forward an on-line shop. In section 5 are presented and briefly discussed some results obtained regarding the main critical success factors studied through a questionnaire carried out in this work. Finally, section 6 puts forward some main conclusions and planned further work.

\section{MARKET DESCRIPTION}

The competitive global market of today requires companies to be in all parts of the world at the same time. E-commerce is a sophisticated tool for opening new business opportunities with a considerable competitive advantage over local markets (Becerra \& Korgaonkar, 2011).

Although there is already a great adherence and growth of e-commerce, it is expected that this still has a high degree of progression.

The demand for niche markets and marketing allies could revolutionize the new ecommerce. Recent technological changes allow cementing online business by providing payment procedures in a safer way up to highly effective logistic companies. The whole process of creating online stores involves many techniques and multidisciplinary areas, requiring a synergy of skills for obtaining the desired result (Brege, Brehmer \& Rehme, 2008). Thus, much attention has to be paid to a variety of subjects related with this issue, including the study of implications of e-commerce at different levels of impact, particularly in terms of human behaviour and preferences, as well as the analysis of alternatives for its implementation.

Understanding what drives an on-line shopper to buy online through a website, as an alternative to traditional commerce is one of the goals that distinguish a successful project, from an inconsequential attempt. A well-known challenge for a successful on-line business 
provider is that it needs involvement from multiple disciplines, such as engineering, design, computing, communications, logistics, marketing and even psychology.

Along with the increasing success of e-commerce in global markets in recent years, especially since middle 1990 s, it has been recognized that e-commerce success has been hampered by a number of reasons. One of which is the lack of conceptual frameworks that can develop and provide effective success measures (Varela, et al., 2016). The work presented in this paper is motivated by this recognition and aims to contribute to the development and provision of an integrated view to define critical success factors for online shopping. The following section will provide a comprehensive literature review on the topic (Burgess, 2008).

\section{REVIEW ON E-COMMERCE}

E-commerce has not evolved at the same rate in quality, although there has been a rapid growth in terms of quantity. The possibility of creating an online store and start selling immediately, without huge investment cost as an obstacle, has provided many people with no relevant knowledge to invest in this area. It is easy to prove this observation by searching online stores which, for instance, simply do not allow the understanding of how one can buy a product when being faced with a confusing website that encourages the user to immediately close the web page, even before take a look on its contents.

Therefore, there is still much room for improvements, by applying the logic of critical success factors. Although there are some online stores performing relatively well, designing an online store without any insightful investigation of potential success factors may turn out to be hard to succeed.

There has been a considerable amount of work carried out to identify, to measure and to evaluate critical success factors in e-commerce during recent years. Those identified, measured and evaluated success factors can be classified using a number of classification schemes (see for example, Cebi, 2013; Chen \& Chou, 2012; Clements, Dean \& Cohen, 2009; Duncan, 2011; Fang, Chiu \& Wang, 2011; ISO, 1998; Joma, 2009; Kawasaki, 2004).

The mainstream on our research in this paper classified success factors into five main categories, i.e. technology acceptance factors, social factors, cognitive factors, ethical factors and environmental factors.

Firstly, technology acceptance factors are mainly focused on the websites, including website quality and website design. Majority of the work identified information quality and system quality as the two main factors to reflect website quality (Cebi, 2013; Chen \& Chou, 2012). Some work extended the website quality to also include service quality (Clements, Dean \& Cohen, 2009). Originally, five dimensions were defined for physical marketplace service quality: tangibles, reliability, responsiveness, assurance and empathy (Kawasaki, 2004). In e-commerce context, methods of measuring success differ from physical marketplace service. E-service quality is therefore defined as the overall customer assessment and judgment of e-service delivery in the virtual marketplace (Clements, Dean \& Cohen, 2009). Website design factors have been diverse; they range from usability and usefulness to interactivity and explicitly (Joma, 2009). Among which, usability is probably the widely discussed factor. For example, does the website have a good structured navigation system for customers to explore the website contents and easily find their desired products or services? Of course, website design and website quality are closely related to each other. Some authors have suggested that website design, fulfilment/ reliability, privacy/ security and customer services are the determinants of customer judgments of quality and satisfaction, customer loyalty and attitudes towards a company's online business (Lee \& Kozar, 2006).

In terms of social factors, those on the top of the list include the sense of virtual community, and the use of social media in online shopping, for example, in the luxury online 
shopping (Fang, Chiu \& Wang, 2011). Online shoppers use blogs, customer reviews etc. to help their purchase decisions. By interacting with other customers, online shoppers feel a strong sense of community and gain satisfaction from others' feedback on the products or services that an online shop provides. Some shoppers think that peer-customers' words are more trustworthy than what specialists' marketing pitches (Lee \& Lin, 2005).

Many other authors have, however, identified trust as an ethical factor. Trust perhaps has been one of the most discussed factors and that is why it spans across both social and ethical categories (Machado, 2011; Ngai, 2003). No matter to which category should trust belong, the basic meanings of trust in the e-commerce context are almost the same, i.e. about practicing privacy policies, describing products and services online objectively and honestly, and maintain transparency of the online business operations (Nielsen, 1994). Some research has even investigated the relationship between knowledge and trust and found a positive relationship between them. Therefore a suggestion is made that online retailing practice should make the public more knowledgeable e.g. about the online transaction security mechanisms in order to build up user's trust in online shopping (Olson \& Boyer, 2005).

Environmental factors to ensure e-commerce success have not been discussed as widely as the other four categories. Only recently, a research on e-commerce trends and development to enhance online customer's satisfaction in China observed three important environmental success factors: government regulations, payment systems, and logistics systems (O'Reilly \& Marx, 2011).

Another interesting classification of success factors is based on the process stages of online shopping. It seems that most research in the context of B2C context agrees on a fourstage process model for online shopping: information, agreement, settlement, and after-sale stages (ISO, 1998; Parasuraman, Zeithaml \& Berry, 1988). A process model for C2C ecommerce (online auction) defined the four stages as information, communication, distribution and transaction (Shahabuddin, 2010). New critical success factors developed in the process models include trade safety, governance and order, reputation and scale, communication channel, information search, transaction process and copious information.

A third classification scheme is more generic, which only have two categories of success factors: customer-centric factors and website-centric factors (Duncan, 2011). The work based on the case of Japan finds out that customers are more concerned about the customer - centric factors, especially customer's education level, creativity, and net-orientation. It seems that Japanese customers do not worry about that much about e-service quality, which is a key success factor in the website-centric category.

Based on the above comprehensive review on literature, it is evident that there have been a huge number of success factors for e-commerce being defined, and that those factors are often discussed in isolation or from a particular perspective, which limits the contribution of existing work to online shop design and implementation practice. E-commerce is a complex e-business process, which requires knowledge from multiple disciplines to make it successful. Therefore, there is a clear need to develop a more advanced framework that can integrate critical success factors from multiple perspectives for online shopping. It is expected that such a multiperspective integrated framework can provide effective guidance to e-commerce provider's design and implementation of successful online stores, as referred in (Burgess, 2008).

\section{ON-LINE SHOPPING CRITICAL SUCCESS FACTORS}

E-commerce is undoubtedly the future that most companies will have to face. However, the fact of creating an online store does not mean guaranteed success.

E-commerce presents fresh challenges that set around a multidisciplinary environment and that must be in harmony, as there are complementary aspects arising from each area, which 
have to be considered and integrated, as a requirement for success (Torkzadeh \& Dhillon, 2002; Suntornpithug, Todorovic, \& Sherrell, 2010).

Just like a real physical shop, also in e-commerce it is not just the commercial part that is implied but a whole set of assumptions that must be guaranteed and controlled. The internet is a medium with its own characteristics, where every detail must be thought out carefully so that the final result is as expected.

Burgess (2008) proposed a multi-perspective model (MPCSF) for critical success factors, which is the base model used in this paper for carrying out a study of critical success factors, included in the MPCSF model that have been considered in an integrated and summarized manner, in the context of on-line shopping and corresponding websites analysis. The authors of this paper (Burgess, 2008) believe that all the success factors should be considered simultaneously from multiple perspectives (technological perspective such as web design usability, social perspective such as social networks, etc.), across different e-commerce life cycle stages (e.g. pre-sale, information stage and supply chain). Their proposed interdisciplinary model includes branding and marketing in Business Management discipline; communication support in Technology and Engineering discipline; and quality data processing in Science discipline. After it is combined with the classification schemes discussed earlier in Section II (i.e. customer-centric and website-centric, and process-based classification).

As stated in (Burgess, 2008), the concept of e-commerce can be viewed as being similar to the solar system, where the e-commerce is the central star and it must include on its orbit all the other stars. Once one of the surrounding stars disappears from its orbit the whole system's stability can be checkmated. Whether for lack of credibility, poor branding concept or simply due to a poor visibility, any failure on one of the factors implies that the project may not work properly and there are plenty of online stores that just do not sell (Burgess, 2008). Next, a summarized view of over an aggregated set of 8 main critical success factors, based on the detailed list of critical success factors described in (Varela et al, 2016) is presented.

\section{Payment security}

With the exponential growth of the Internet shopping, security has been the major concern of users. However, increasingly more money transactions take place and the systems are becoming considerably safer. Selecting safe payment methods and be at the forefront of information technology about security issues, is a competitive advantage on on-line selling. Thus, if the client is aware about the on-line shop concerns to ensure secure payment transactions, the brighter the image of trust and responsibility will be passed to potential clients.

Although the world is aware that issues about security breaches continue to rise on data computing and Internet transactions, and as even the most protected systems are transposable, we must maintain the dedication to guarantee purchases as much secure as possible. Moreover, to attract online customers e-commerce business should understand the customers' real wishes and expectations and what payment methods each type of segment of users does prefer. Each marketplace has its peculiarities and consumers tend to create common purchasing habits with which they feel more comfortable, e.g. "to use the online shopping cart" (Thorleuchter \& Van Den Poel, 2012).

\section{Website userfriendliness}

Websites user-friendliness is nowadays a growing exigency of customers, as social networks have changed the way people communicate, enabling to reinvent something we did naturally, with a slower speed. The initial idea was aimed at friends to join on a virtual network where they could communicate about everyday's life. This phenomenon has exceeded expectations 
and inevitably began to move towards the business world. If customers are concentrated on a particular community, nothing is more natural than participating on it.

Nowadays, all major brands present themselves within this environment, trying to reach a huge market with a multiplying growing effect (Suntornpithug, Todorovic \& Sherrell, 2010). Applying the phenomenon of social networks to e-commerce, has the additional advantage of reaching people that are already regular users of the Internet, and to capture their attention to new products and services requires a good communication and marketing strategies to be implemented. Thus, one can gain customers through these communication engines, enhancing the target market.

Another important aspect of websites' user-friendliness relies on the underlying website's usability. In an on-line shop the customer interface occurs via the website, therefore, their expectations have to be met as they easily may move away to the competition. Therefore, one crucial issue on the design of any information system is the usability of the user's interface. According to ISO 9241 - Part 11 (1998) usability is defined as the effectiveness, efficiency and satisfaction with which specific users achieve goals in particular environments. These definitions relate directly with 3 questions: How can users perform their tasks? What resources must users spend to achieve a given outcome (e.g., time, effort)? How well do users like the application?

Besides the economical costs (i.e. a system that is hard to understand is also hard to sell, and may involve many expensive problems in its life cycle), the lack of care about users needs can lead to solutions that tend to cause errors or that provide users with inadequate information. For e-commerce, this is particularly harmful because it implies losing customers (Thorleuchter \& Van Den Poel, 2012).

Usability is an essential critical success factor to take in consideration in the design of websites because it is not a single, one-dimensional property of a user interface. Usability has multiple components and is traditionally associated with five usability attributes: learnability, efficiency, memorability, errors, and satisfaction (Tu, Yen \& Hou, 2010).

\section{Business brand and confidence}

Knowing our business can help to know, "where we are" and "where we want to go" (Alturas, Santos \& Brites, 2006). Measuring performance at each step of business allows adjusting measures to consider and values to obtain, through a sustained growth. This measurement is only possible if there are predefined and measurable goals for market trends. Therefore, it is necessary to know if it is a marketplace of thousands, millions or billions.

The more information available the better our position will be to support good decision making strategies. Understanding the marketplace is the first step, setting goals is the second one and nothing serves the former if there is no continuous analysis of results obtained.

In order to completely fulfil the whole requirements inherent to a successful business, it is of upmost importance to know the world of brands, as it moves millions, as increasingly more companies look for convincing brands, to better affirm themselves among competitors (Suntornpithug, Todorovic \& Sherrell, 2010). In e-commerce the paradigm does not change, to buy online, you need something to push you to finalize your purchase. It is not enough to think that a brand is just a cute name or a futuristic logo, the whole communication with the surroundings has to be well thought, and the care and concern about the customers need to be visible in order to enable to construct a loyalty based relation with them (Suntornpithug, Todorovic \& Sherrell, 2010).

The concept of a brand has to have the objective to be a precise way to reach the clients and establish a collaborative interaction with them by enabling integration of different areas. Impact, desire and trust are the ingredients that may enable a common brand to become a 
benchmark worldwide. If the main purpose of the brand is not describable by a few words, it is most probably not well designed.

\section{Website effectiveness}

Regarding expectations of users to find the products they are looking for website's

effectiveness plays a crucial role because once achieved the complete flow of the market to the online shop, there is still another important but less explored subject, which consists on being able to convert a visitor into a customer (Tsai, Cheng \& Chen, 2011).

With the tools available on the market it is possible to analyze many details about visits to a website. From the time each user wastes browsing, up to the number of visitors per day, broken down by country and other indicators, many different kind of analysis are possible.

When the number of visits to a website is big and the sales have not risen, something must be done to reverse potential customer's bad attention. Issues related to websites effectiveness and usability, communication and marketing problems must be completely revised to ensure ecommerce success.

\section{Marketing strategy}

Using an appropriate marketing strategy along with an improved business offered and other non-technological areas are crucial multidisciplinary requirements for the success of ecommerce. Moreover, once a brand is defined - and this applies to any product - it needs to be recognized as a reference. A well structured marketing plan, with a well-defined line and an innovative and credible image are essential success factors for promoting any brand or product (Alturas, Santos \& Brites, 2006).

From videos and images up to workshops and international conferences, it is worth using all channels of communication to solidify the brand on the market. Thus, it becomes a necessity to innovate and to re-invent the way we present ourselves to the world (Wolfinbarger \& Gilly, 2003).

Although a segment of the Marketing, the Web- Marketing deserves special mention, for conceiving a fantastic store, in terms of design and image, may seem to be good enough for becoming very successful. However, imagine how disastrous it would be if no one would pass on the street where the shop is located and the same may happen regarding online stores (http://www.acepi.pt).

Search engines provide the initial dialogue between consumers and online stores; therefore a good positioning or ranking of a website is of utmost importance. Search engines, like Google, also have tools to measure how many times certain words are searched and analyze all statistical data about the number of visitors about a given online store. Hence, improving search strategies is another important success factor.

There are several ways for enabling good rankings of websites within searching engines, which turns out to be even more important when a website includes sponsored links. The best way to attract potential customers is to accurately know the market where it operates, so that the whole effort is focused in favour of the business (Suntornpithug, Todorovic \& Sherrell, 2010).

\section{After-sales support service}

When buying on an online store, its success is only possible if there is a satisfactory level of communication support along the entire supply chain, which must be synchronized and integrated (Wu, Tao \& Wang, 2007). A climate of trust and sharing must prevail, so that the whole quality of the system is reflected on the final consumer (Yuen, 2010). 
If the manufacturer and all intermediaries are not sharing the same values, the whole communication within the supply chain may be compromised and the concept of a successful online store will most probably fall. Imagine how disastrous it would be having a welldesigned online store, with a powerful marketing and numerous customers and the delivery due dates of the products were constantly being violated (O'Brien, 2015).

Only the skilled ones can be a part of the successful communication and supply chain, for each one, on its "core business", to provide its best possible contribution, always focused on reaching integration and common objectives and customer satisfaction.

The clients and their satisfaction must be constant concerns of any company aspiring to reach a sustainable growth (Torkzadeh \& Dhillon, 2002). Moreover, in a medium like the internet, additional concerns about the fact that many users still do not feel comfortable buying products they cannot physically see, have to be kept on mind. One central concern of a consumer is about knowing if the website provides support to clarify questions about products or services; and, in particular, issues related to product returns or simply about how to get more direct information about the provided products and/ or services. With the growth of the Internet there are also many online shops whose quality standards do not meet customer requirements, installing uncertainty on the marketplace.

It is of utmost importance to provide a full service support, before, during and after purchase. This way the clients feel supported and understood and not afraid to repeat the experience and buy through the same website.

The word "guarantee" frightens many entrepreneurs; however, this paradigm must change as people buy more if they feel fully supported and "safe" and in the majority of online stores the rates about product returns are quite low company aspiring to reach a sustainable growth (Torkzadeh \& Dhillon, 2002).

\section{Company's credibility}

Regarding marketing strategies to incentivize anyone to buy through an online store, there are still many entrepreneurs targeting cost reduction instead of investing on that direction to enrich online stores' credibility. A shop with an "amateur" aspect easily distracts consumers that are more already suspicious about online shopping.

A good call centre, setting up a company with physical office, a registered trademark and the overall design and functionality of the website should not be jeopardized due to a low budget. Moreover, being professional and combining all these details will help strengthen the credibility of the store. Another key factor consists on joining forces and partnering with credible companies (Wu, Tao \& Wang, 2007).

The overall credibility of an on-line store is visible when it is working perfectly, without any bugs or links that do not work. When usability is jeopardized and something stops working and confuses the user this may compromise the quality of the whole website and the underlying information system project, along with the correct functioning of the communication channels and the underlying operation of the supply chain, which is essential to gain the users confidence.

Moreover, the quality of the delivered product and/or services can be compromised while lacking quality data processing, therefore, it is also of upmost importance to ensure quality data processing (Schubert, 2002).

\section{General website quality}

The website is a showcase of the online store, which has to take into account to whom it should attract attention, as its mere existence does not mean its success. The whole construction of the website must be developed by a multidisciplinary team because there are several areas that will 
be involved for achieving the final product with the intended image and functionality. For example: the programmer may build the website quite clearly, without any bugs or technical problems, but if the designer does not provide an efficient interface it probably will fail (Schubert, 2002).

Therefore, all those multidisciplinary areas should be taken in consideration on the creation of any website, so that each area can provide an important contribution to its final result. Any successful e-commerce website must be robust, complete, appealing and balanced to ensure passing an image of a serious and credible company, without any tendentious reflection just about a particular area or concern.

The next section presents the study undertaken and analyses the impact of these main critical success factors on existing websites.

\section{DATA ANALYSIS AND DISCUSSION}

In this study 12 websites (WS1 to WS12) about luxurious furniture, were analysed in order to understand the set of 8 main characteristics on these websites. These 8 main critical success factors (CSF1 to CSF8), are given upmost importance, for evaluating websites, according to the description previously presented. Table 1 provides a list of the 12 websites and the corresponding links.

Table 1. Websites analysed

\begin{tabular}{|c|l|}
\hline WS number & Website link \\
\hline WS1 & $\underline{\text { http://www.bernadettelivingston.com/ }}$ \\
\hline WS2 & $\underline{\text { http://www.williams-sonoma.com/ }}$ \\
\hline WS3 & $\underline{\text { http://www.juliettesinteriors.co.uk/ }}$ \\
\hline WS4 & $\underline{\text { http://www.taylorllorentefurniture.com/ }}$ \\
\hline WS5 & $\underline{\text { http://www.horchow.com/ }}$ \\
\hline WS6 & $\underline{\text { http://www.luxuryfurnitureandlighting.com/ }}$ \\
\hline WS7 & $\underline{\text { http://www.scalaluxury.com/ }}$ \\
\hline WS8 & $\underline{\text { https://www.savannahcollections.com/ }}$ \\
\hline WS9 & $\underline{\text { http://www.ikandi-interiors.com.uk/ }}$ \\
\hline WS10 & $\underline{\text { http://www.greenfront.com/ }}$ \\
\hline WS11 & $\underline{\text { http://www.furniture.mj777.com/index_en.htm }}$ \\
\hline WS12 & $\underline{\text { http://www.ramobili.it/ }}$ \\
\hline
\end{tabular}

The 8 main critical success factors (CSF) that were analysed along the 12 websites are:

CSF1) Payments security

CSF2) Website user friendliness

CSF3) Business brand and confidence

CSF4) Website effectiveness

CSF5) Marketing strategy

CSF6) After-sales support service

CSF7) Company's credibility

CSF8) General website quality 
In this study a set of 70 qualified users on systems analysis were inquired, about each of the 8 main CSFs, for being evaluated on the 12 websites referred above, on a range from 0 to 3 , as follows:

$$
\begin{aligned}
& 0 \text { - the CSF is not applied } \\
& 1 \text { - the CSF is fairly applied or satisfied } \\
& 2 \text { - the CSF is suitably applied or satisfied } \\
& 3 \text { - the CSF is completely applied or satisfied }
\end{aligned}
$$

The results obtained for each CSF are presented in the next sections. The evaluations attributed to each CSF by the inquired individuals in a range varying from 0 to 3 points, are graphically represented in the following eight graphics.

\section{Payments security}

The results obtained for the payment security critical success factor (CSF1) are shown in Figure 1.

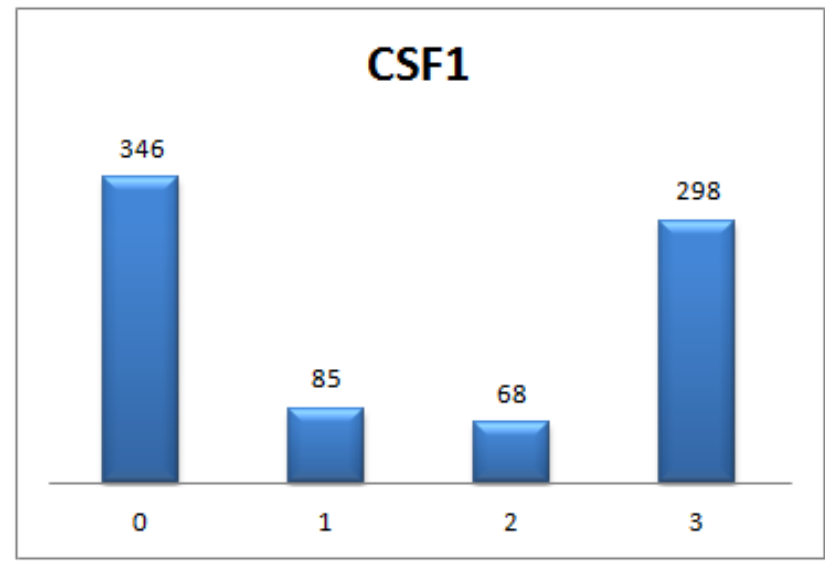

Figure 1. Payment security results (CSF1).

As we can realize through the results presented on Figure 1, for this CSF1, about payment security, around $43.4 \%$ of the answers reveal that payment security is not applied; $10.7 \%$ of the answers reveal that it is fairly applied or satisfied; $8.5 \%$ of the answers reveal that it is suitably applied or satisfied; and $37.4 \%$ of the answers reveal that it is completely applied or satisfied.

According to the results obtained we may realize that payment security is a CSF that is not always clearly satisfied, which can drastically penalize on-line stores.

\section{Website userfriendlyness}

The results obtained for the website user-friendliness critical success factor (CSF2) are shown in Figure 2.

As we can realize through the results presented on Figure 2, for this CSF2, about website user-friendliness, around $20.0 \%$ of the answers reveal that website user-friendliness is not existing; $24.6 \%$ of the answers reveal that it is fairly existing; $24.7 \%$ of the answers reveal that it is suitably existing; and $30.7 \%$ of the answers reveal that it is completely existing or satisfied. 


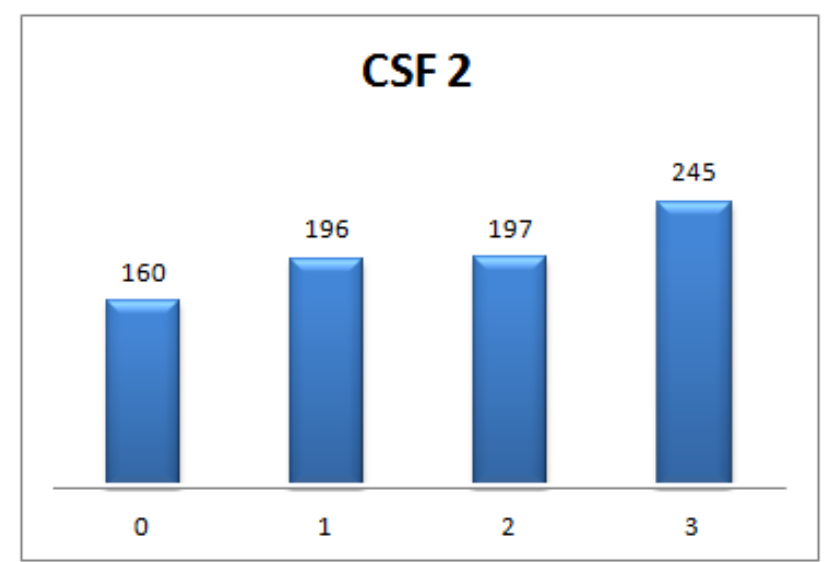

Figure 2. Website user-friendliness (CSF2).

According to the results obtained we may realize that although we can notice a good strength regarding website user-friendliness improvement is a CSF that is not always clearly satisfied, which can punish on-line stores.

\section{Business brand and confidence}

The results obtained for the business brand and confidence critical success factor (CSF3) are shown in Figure 3.

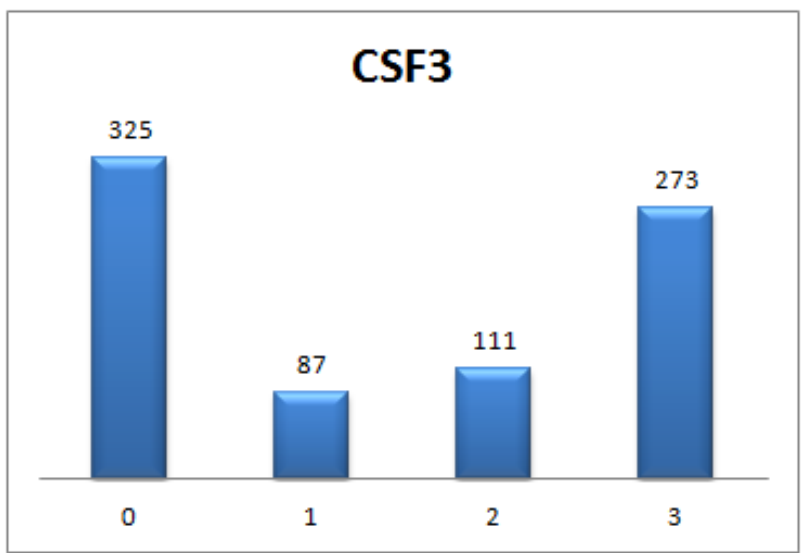

Figure 3. Business brand and confidence (CSF3).

As we can realize through the results presented on Figure 3, for this CSF3, about business brand and confidence, around $40.8 \%$ of the answers reveal that business brand and confidence is not existing or satisfied; $10.9 \%$ of the answers reveal that it is fairly existing or satisfied; $13.9 \%$ of the answers reveal that it is suitably existing or satisfied; and $34.4 \%$ of the answers reveal that it is completely existing or satisfied.

According to the results obtained we may realize that business brand and confidence is a CSF that does not always undoubtedly exist, which can severely reprimand on-line shopping.

\section{Website effectiveness}

The results obtained for the website effectiveness critical success factor (CSF4) are shown in Figure 4.

As we can realize through the results presented on Figure 4, for this CSF4, about website effectiveness, around $8.8 \%$ of the answers reveal that website effectiveness does not exist or 
satisfied; $28.1 \%$ of the answers reveal that it is fairly existing or satisfied; $18.9 \%$ of the answers reveal that it is suitably existing or satisfied; and $44.2 \%$ of the answers reveal that it is completely existing or satisfied.

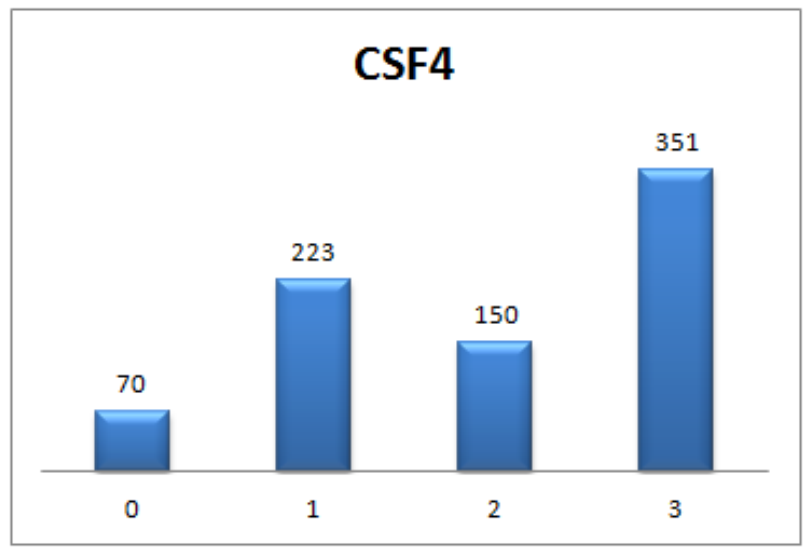

Figure 4. Website effectiveness (CSF4).

According to the results obtained we may realize that website effectiveness is a CSF that does seem, in general, to be quite acceptably satisfied, which reveals a growing effort taken in the direction of persuading potential clients to buy on-line.

\section{Marketing strategy}

The results obtained for the marketing strategy critical success factor (CSF5) are shown in Figure 5.

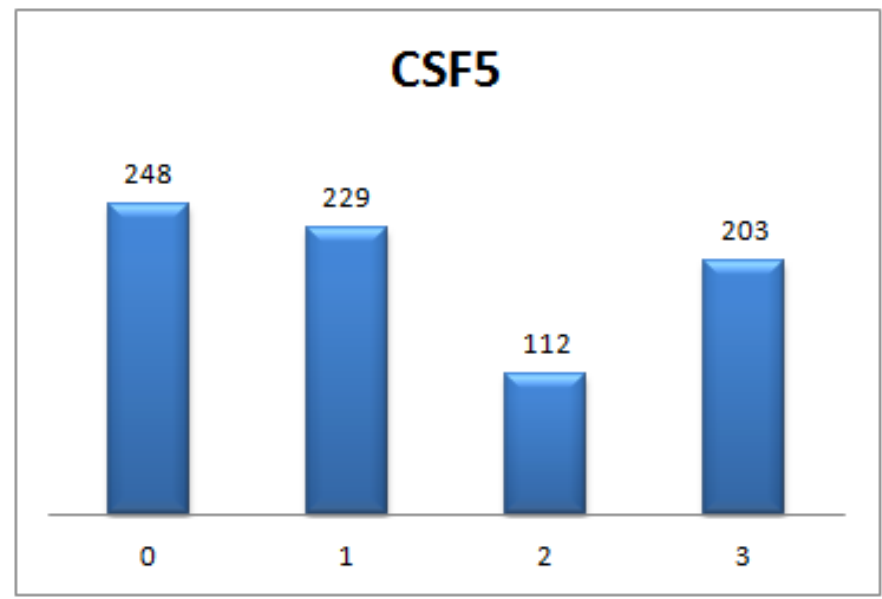

Figure 5. Marketing strategy (CSF5).

As we can realize through the results presented on Figure 5, for this CSF5, about marketing strategy, around $31.3 \%$ of the answers reveal that marketing strategy is not applied or visible; $28.9 \%$ of the answers reveal that it is fairly applied; $14.2 \%$ of the answers reveal that it is suitably applied or satisfied; and $25.6 \%$ of the answers reveal that it is completely applied or satisfied.

According to the results obtained we may realize that although we can notice a good strength regarding market strategy concerns is a CSF that is not always clearly satisfied, which can negatively affect on-line stores. 


\section{After-sales support service}

The results obtained for the after-sales service critical success factor (CSF6) are shown in Figure 6.

As we can realize through the results presented on Figure 6, for this CSF6, about aftersales service, around $32.3 \%$ of the answers reveal that after-sales support service does not exist; $21.9 \%$ of the answers reveal that it is fairly existing; $17.2 \%$ of the answers reveal that it is suitably implemented; and $28.6 \%$ of the answers reveal that it is fully implemented.

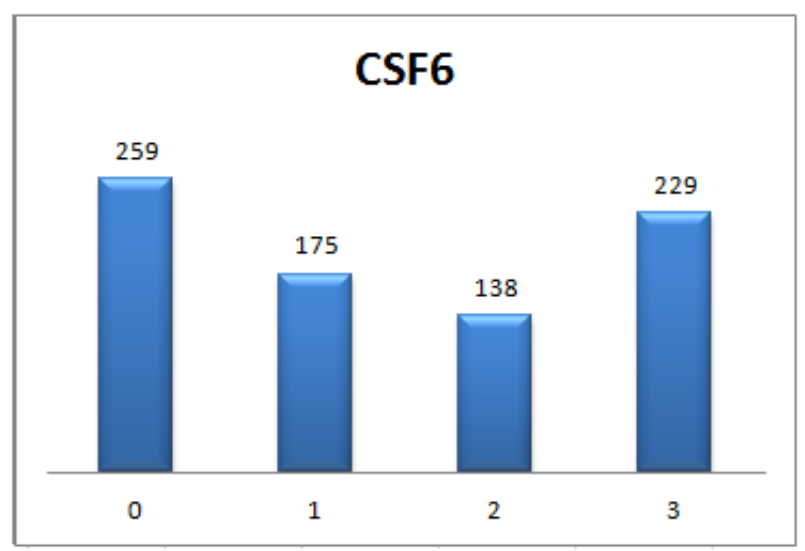

Figure 6. After-sales support service (CSF6).

According to the results obtained we may realize that after-sales support service is a CSF that does not always clearly exist, which can penalize the success of on-line stores.

\section{Company's credibility}

The results obtained for the company's credibility critical success factor (CSF7) are shown in Figure 7.

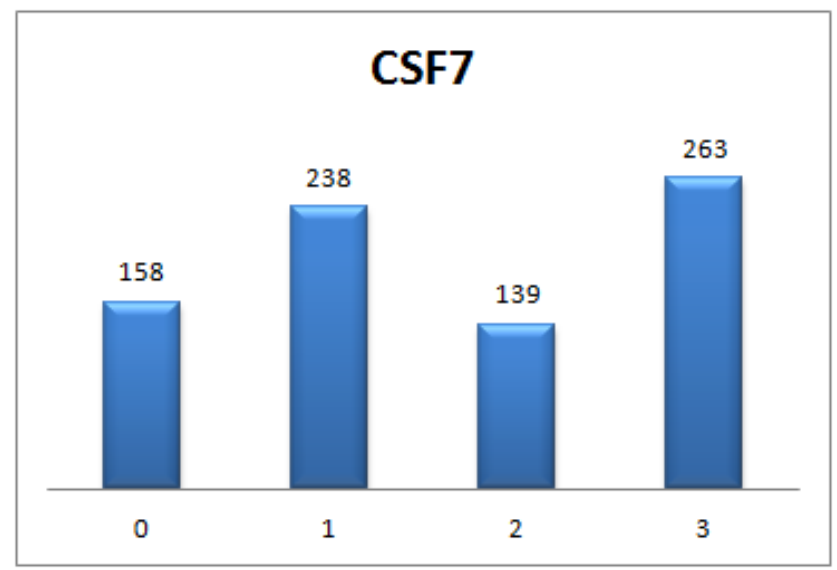

Figure 7. Company's credibility (CSF7).

As we can realize through the results presented on Figure 7, for this CSF7, about company's credibility, around $19.8 \%$ of the answers reveal that company's credibility is not visible; $29.8 \%$ of the answers reveal that it is fairly visible; $17.4 \%$ of the answers reveal that it is suitably visible; and $33.0 \%$ of the answers reveal that it is completely noticeable. 
According to the results obtained we may realize that company's credibility is a CSF that does seems, in general, to be a concern of companies for being satisfied, in order to attract potential clients to buy on-line.

\section{General website quality}

The results obtained for the general website quality critical success factor (CSF8) are shown in Figure 8.

As we can realize through the results presented on Figure 8, for this CSF8, about the general website quality, around $25.9 \%$ of the answers reveal that general website quality is very poor; $20.8 \%$ of the answers reveal that it is fairly satisfactory; $26.6 \%$ of the answers reveal that it is good; and $27.6 \%$ of the answers reveal that it is excellent.

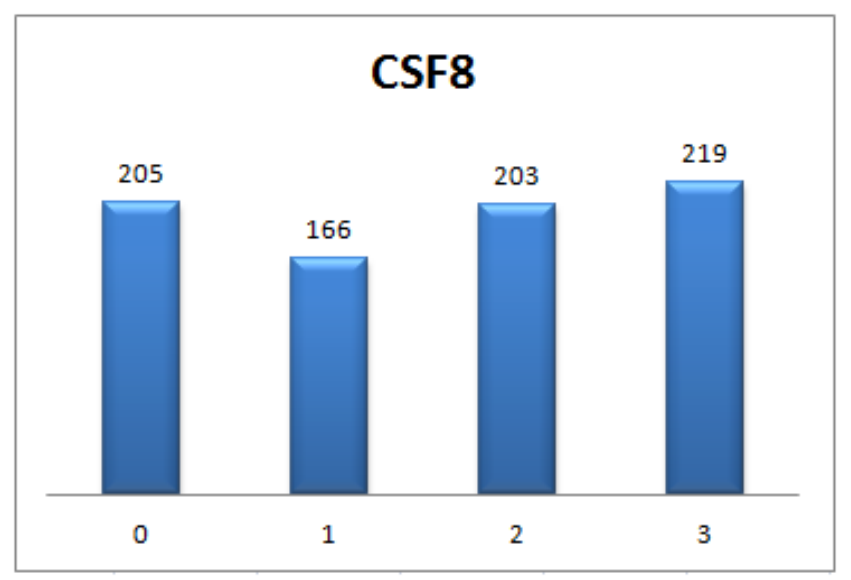

Figure 8. General website quality (CSF8).

According to the results obtained we may realize that general website quality is a CSF that appears to be a concern of companies. Although a growing effort has to be taken in this direction to improve quality of on-line shopping services.

\section{CONCLUSION}

As represented in the overall representation of Figure 9, the critical success factor "Website effectiveness" is the only one presenting a graduation of suitably satisfied (1.99), and the worse ranked are "Marketing strategy" (1.34) and "Payment security results" (1.40). 


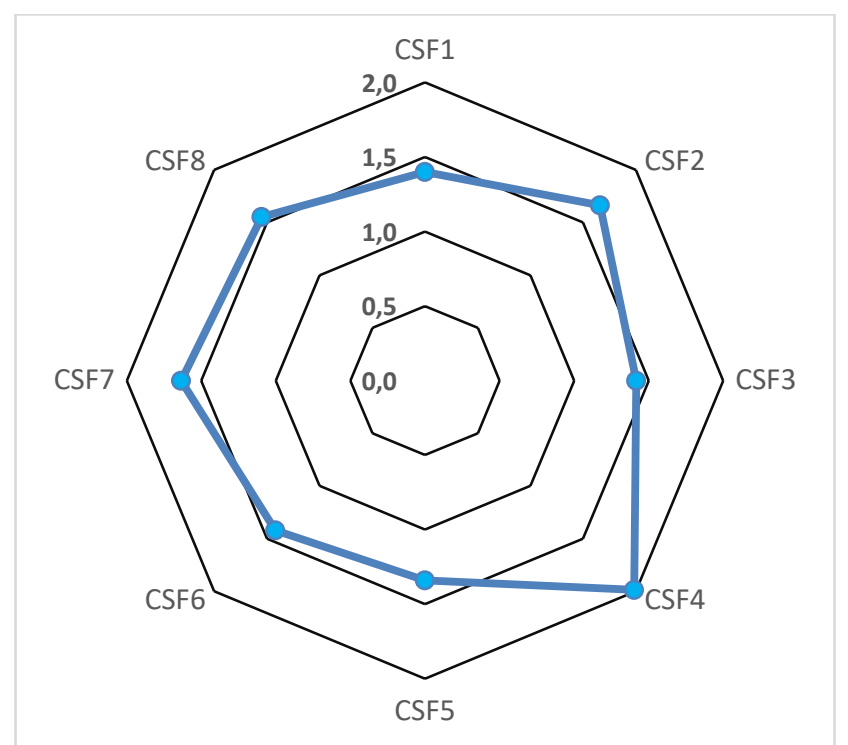

Figure 9. Weighted average evaluation for the eight CSF

Knowing the necessary ingredients for success in e-commerce is crucial to build a highly profitable and consistent e-commerce business strategy. Building an online shop based on a fully satisfied critical success factors will enable a successful on-line business and transmit confidence to potential on-line clients.

Therefore, it is of upmost importance not to distract customers, while compromising the balance of a whole website. There is still plenty of room for improvement in the market of online shops, as more and more people choose this way of shopping, which enables entrepreneurs to get closer to its market, while presenting an appropriate solution for their clients' expectations. Moreover, it is necessary to pay attention to aspects for enabling a good e-commerce practice. Often those aspects are under estimated due to lack of analysis and investigation regarding a set of proposed success factors described through this work.

The proposed set of main critical success factors described and analysed in this paper are not only related to the website itself, its design and usability, but also to other considered very important ones, such as: the brand; the marketing and web-marketing strategies; including social networks reaching; concerns about the whole supply chain integration; concerns regarding consumers conversion, communication and support; looking at quality data processing and secure payment methods; and enabling a favourable image for reaching on-line shop credibility. Compared with existing conceptual models for e-commerce success factors in the literature, there are some relevant contributions of our proposal, including: The definition of proposed critical success factors such as converting customers and credibility; the proposal to include stages beyond the existing online shopping life cycle, i.e. it considering not only the information phase, agreement phase, transaction phase and delivery phase, but also the preand after-sale phases; also incorporating the critical success factors from multiple perspectives - technology, social and ethical perspective; and integrating knowledge from multiple disciplines such as Engineering, Science and Technology, and Business Management. Therefore, the proposed critical success factors can provide a more comprehensive understanding of on-line shopping in order to achieve business success.

In addition it has been identified that a more professional attitude is needed, as all these factors are of major importance for ensuring the difference between a modest online store and an online empire. 


\section{ACKNOWLEDGMENT}

This work has been supported by COMPETE: POCI-01-0145-FEDER-007043 and FCT - The Foundation for Science and Technology within the Project Scope: UID/CEC/00319/2013.

\section{REFERENCES}

Abdallah, S., \& Jaleel, B. (2014). Online Shopping in the United Arab Emirates: International Journal of Web Portals, 6(1), 1-20. https://doi.org/10.4018/ijwp.2014010101.

Alturas, B., Santos, M. D. C., \& Brites, R. (2006). Direct Selling: Finding Consumer Segments. In Proceedings of the EIRASS International Conference (p. 8).

Ascensão, C. P. (2011). Google Marketing: A arma mais poderosa para atingir os seus clientes.

Bandyopadhyay, N. (2010). A conceptual understanding of the impact of marketspace on the four P's of marketing. International Journal of Electronic Customer Relationship Management, 4(1), 33-42.

Becerra, E. P., \& Korgaonkar, P. K. (2011). Effects of trust beliefs on consumers' online intentions. European Journal of Marketing, 45(6), 936-962.

Brege, S., Brehmer, P. O., \& Rehme, J. (2008). Managing supplier relations with balanced scorecard. International Journal of Knowledge Management Studies, 2(1), 147-161.

Burgess, S. (2008). Determining website content for small businesses: assisting the planning of owner/managers. International Journal of Knowledge Management Studies, 2(1), 128146.

Cebi, S. (2013). Determining importance degrees of website design parameters based on interactions and types of websites. Decision Support Systems, 54(2), 1030-1043.

Chen, Y. T., \& Chou, T. Y. (2012). Exploring the continuance intentions of consumers for B2C online shopping: Perspectives of fairness and trust. Online Information Review, 36(1), 104-125.

Clements, M. D., Dean, D. L., \& Cohen, D. A. (2009). Supplier selected relationships: choosing friends, over family. International Journal of Manufacturing Technology and Management, 19(1-2), 47-67.

Cunha, M. M., Putnik G. D. \& Gunasekaran, A. (2003). Market of resources as an environment for agile/virtual enterprise dynamic integration and for business alignment. In Knowledge and information technology management: Human and social perspectives (pp. 169-190).

Cruz-Cunha, M. M., \& Putnik, G. D. (2009). Environments for virtual enterprise integration. In M. M. Cruz-Cunha (Ed.), Social, Managerial, and Organizational Dimensions of Enterprise Information Systems (pp. 194-211). Hershey, PA: IGI-Global. https://doi.org/10.4018/978-1-60566-856-7.ch010

Duncan, K., 2011. Marketing Greatest Hits. First Edition.

Fang, Y. H., Chiu, C. M., \& Wang, E. T. (2011). Understanding customers' satisfaction and repurchase intentions: An integration of IS success model, trust, and justice. Internet Research, 21(4), 479-503.

Ferreira, L., Putnik, G., Cunha, M., Putnik, Z., Castro, H., Alves, C., Shah, V. \& Varela, M. L. R. (2013). Cloudlet architecture for dashboard in cloud and ubiquitous manufacturing. In Procedia CIRP (Vol. 12). https://doi.org/10.1016/j.procir.2013.09.063

ISO, W. (1998). 9241-11. Ergonomic requirements for office work with visual display terminals (VDTs). The international organization for standardization, 45.

Joma, S.I., 2009. Research on e-commerce trends and development to enhance online customer satisfaction in China. In proceedings of the 8th Wuhan Interntaional 
Conference on E-business (editor: Duserick, F.G.). volumes 1-3, pages 94-99. 30th-31st May 2009, Wuhan, China.

Kawasaki, G., 2004. The Art of the Start.

Lee, G. G., \& Lin, H. F. (2005). Customer perceptions of e-service quality in online shopping. International Journal of Retail \& Distribution Management,33(2), 161-176.

Lee, Y., \& Kozar, K. A. (2006). Investigating the effect of website quality on e-business success: An analytic hierarchy process (AHP) approach. Decision support systems, 42(3), 1383-1401.

Machado, A. T. M., 2011. Usability: Impact on E-commerce. PhD Thesis, Technical University of Lisbon.

Ngai, E. W. T. (2003). Selection of web sites for online advertising using the AHP. Information \& Management, 40(4), 233-242.

Nielsen, J. (1994, April). Usability inspection methods. In Conference companion on Human factors in computing systems (pp. 413-414). ACM.

O’Brien, T. (2015). 'Accounting' for Data Quality in Enterprise Systems. Procedia Computer Science, 64, 442-449.

Olson, J. R., \& Boyer, K. K. (2005). Internet ticketing in a not-for-profit, service organization: building customer loyalty. International Journal of Operations \& Production Management, 25(1), 74-92.

O'Reilly, K., \& Marx, S. (2011). How young, technical consumers assess online WOM credibility. Qualitative Market Research: An International Journal, 14(4), 330-359.

Parasuraman, A., Zeithaml, V. A., \& Berry, L. L. (1988). Servqual. Journal of retailing, 64(1), 12-40.

Schubert, P. (2002). Extended Web Assessment Method (EWAM): Evaluation of electronic commerce applications from the customer's viewpoint. International Journal of Electronic Commerce, 7(2), 51-80.

Shahabuddin, S. (2010). Supply Chain Management and its effect on company's performance. International Journal of Logistics Systems and Management, 8(1), 101-117.

Suntornpithug, N., Todorovic, Z. W., \& Sherrell, D. L. (2010). Revisiting the concept of person interactivity through social psychology and social telepresence theory. International Journal of Electronic Business, 8(1), 31-50.

Thorleuchter, D., \& Van Den Poel, D. (2012). Predicting e-commerce company success by mining the text of its publicly-accessible website. Expert Systems with Applications, 39(17), 13026-13034.

Torkzadeh, G., \& Dhillon, G. (2002). Measuring factors that influence the success of Internet commerce. Information Systems Research, 13(2), 187-204.

Tsai, M. T., Cheng, N. C., \& Chen, K. S. (2011). Understanding online group buying intention: the roles of sense of virtual community and technology acceptance factors. Total Quality Management \& Business Excellence, 22(10), 1091-1104.

Tu, H. J., Yen, W. C., Hou, J. J., 2010. Measuring the operating efficiency of internet channels with DEA. In: Int. J. Logistics Economics and Globalisation, Vol. 2, No. 2. Inderscience Enterprises Ltd.

Varela, M. L. R., Ferreira, M. F., Vieira, G. G., Manupati, V. K., \& Manoj, K. (2016, June). A multi-perspective integrated framework of critical success factors for supporting on-line shopping. In Information Systems and Technologies (CISTI), 2016 11th Iberian Conference on (pp. 1-6). AISTI.

Varela, M. L. R., Putnik, G. D. \& Cruz-Cunha, M. M. (2012). Web-based Technologies Integration for Distributed Manufacturing Scheduling in a Virtual Enterprise. 
International Journal of Web Portals, 4(2), 19-34.

https://doi.org/10.4018/jwp.2012040102

Wolfinbarger, M., \& Gilly, M. C. (2003). eTailQ: dimensionalizing, measuring and predicting etail quality. Journal of retailing, 79(3), 183-198.

Wu, Y.L., Tao, Y.H., and Wang, T.C., 2007. Critical success factors for online C2C auction websites - a consumer's perspective. In Proceedings of the 6th WSEAS International Conference on Applied Computer Science. Book series "Electrical and Computer Engineering". Pages: 54-59.

Yuen, S. S. (2010). Development of electronic marketplace for collaborative supply chain: a conceptual framework. International Journal of Enterprise Network Management, 4(1), 59-67. 